Journal of the Scholarship of Teaching and Learning, Vol. 20, No. 3, December 2020, pp. 1-19.

doi: 10.14434/josotl.v20i3.24487

\title{
Contextual Framework for Developing Research Competence: Piloting a Validated Classroom Model
}

\author{
Lynn M. Jamieson. Re.D. \\ Indiana University \\ lyjamies@,indiana.edu
Mark V. Saunders, Ph.D.
Indiana University
marsaund@indiana.edu

\begin{abstract}
The goal of most researchers is to establish competence in one's profession; however, the degree to which this is measured in a research course is undetermined. The assessment of research competency usually involves the distinct measures of statistical ability, writing ability, and other skills that are quantifiable. Soft skills in research, on the other hand, are less distinguishable. It was the intent of this study to review eight years of data collection in undergraduate and graduate research classes to determine if a set of specific assignments was successful in developing the soft skills of research competence. Through a qualitative assessment, evaluation of visual materials, and assessment of a research instructional video, it was found that, to some extent, isolated and specific whole-part-whole, in-class and in-field assignments for the individual student or students within small groups, might allow students to develop the bard and soft skills necessary to become competent as researchers or their chosen profession.
\end{abstract}

Keywords: assessment, effectiveness, hard and soft skills, whole-part-whole learning.

What are the qualities that help to develop a competent researcher? Is it the number and type of published articles, a particular research approach, unique methodology, and the effective dissemination of information or other similar qualities? Furthermore, is it observational effectiveness, writing skills, superior judgment, or are there other measures? The purpose of this study identified and evaluated selected assessment tools that measure the soft and hard skills in-regard to the concept of research competence within the curriculum. In addition, the value of a visual representation of research skills in the form of a visual enhancement tool, was explored to determine if the use of video learning enhanced student understanding of the hard and soft skills necessary to become a competent researcher.

The ultimate goal of most researchers is to establish competence in one's field of expertise. Similarly, undergraduate and graduate curricula provide a multitude of ways to evaluate whether someone attains the required standards within a course, class, or degree. Generally, it is known that cognitive, affective, and culturally responsive means exist to maximize student learning (Durlak, 2011). These areas of learning typically form the basis for providing students with learning experiences that meet, and or exceed the minimum standards.

According to Watson (1994) the attainment of competence consists of three main areas: 1) assessment based on samples of performance, 2) assessment based on natural observation in the workplace, and 3) assessment based on evidence from prior achievements (p. 157). Therefore, the attempt to achieve a resemblance of research competence in the classroom setting is challenged by the need to reflect what actually occurs in the natural environment and the work place. Simulating these experiences in the classroom allows students to begin to understand and plan for workplace expectations with regard to research preparedness. 
In particular, many practitioners who struggle with training professionals to develop these skills support the need to assess research competence. McCrystal (2000) notes the essential value of a Practitioner Research Training Program for social work researchers. The program content includes how research literacy impacts the social work profession and its value being integral to practitionerresearcher partnerships. This approach is representative of an early concern over quality research, and researcher competence (McCrystal, 2000). To illustrate this point, over a two-year period, issues from the Chronicle of Higher Education featured articles that had to do with concerns over the quality of research and the competence of researchers. Incidents were cited dealing with inadequate protection of human subjects, researcher ethics, validity of instruments for evaluation and assessment, statistical veracity, clear writing skills, political and corporate pressures to come up with answers, and numerous other problems (Best, 2001; Kahn, 2002; Small, 2000, White, 2000).

With regard to research ethics and the use of human subjects, it was noted as being addressed through the implementation of education and assessment. However, in response to concerns over researcher ethics, human subjects review boards were tightening research standards to ensure protection of subjects (Coleman, 2009). There was also an incipient trend toward greater research collaboration with public research universities and the public and private sectors. For instance, according to Yudof (2002), "The $21^{\text {st }}$ century will see the evolution of a hybrid public research university, one with roots in both the public and private spheres" (p. B24).

Concurrently, there was growing awareness of the importance placed on research in daily life: i.e., research translating into practice. Practical uses, such as database research, are employed when an agency or business analyzes useful information generated from within the organization. Accidents, sick leave, level of work completed, demographic composition of employees and similar statistics, may be generated from an aggregated database developed in the workplace.

An example of the types of skills sought to certify a technically competent researcher are those depicted for dentists that consist of five domains: practical application of skills; solving problems; communication and thinking skills; personal and professional attitudes/ethics; distribution of findings; and assuming the function of the researcher role (Research competencies framework, 2007). The varied range of research competency noted in the faculty driven efforts include not only technical skills for conducting research, but also ancillary skills involving thinking and attitudinal aspects of the research process. For example, Arellano, Morano, and Nepomucheno (2012) tested 963 graduating students with a two-part questionnaire to determine their perceptions of research proficiency. The results showed that while certain aspects of the research process were attained, less than one half of the respondents were confident in dealing with hypothesis testing, developing appropriate scales, and identifying the appropriate statistical analysis for the project. They also tested poorly on outlining the general steps in conducting a research problem. Thus, one of the conclusions of this study was that the students were poorly equipped on certain aspects of research competence (Arellano, 2012).

What has been less evident is the assessment of competence that could be part of an overall course outcome. When completing the course, are students truly prepared to conduct research? Present within some research course assignments are areas of concern that should include overarching soft skills such as: customer service, public relations, and political savvy. More specifically, the soft skills noted in this course were patterned after those suggested in the above dentist example: practical application of skills, solving problems, personal and professional attitudes/ethics, assuming the function of the researcher role, and distribution of findings (Research competencies framework (2007). It appears that the soft skills per se, are needed to attain research competence and are not typically addressed and/or evaluated. Research skills of writing, number crunching, and analysis appear in most research courses; however, the soft skills of interviewing techniques, observational skills, and other similar areas have often not appeared in the curriculum. There seems to be an assumption that these skills will develop with experience; however, it is not clear whether these skills should be developed

Journal of the Scholarship of Teaching and Learning, Vol. 20, No. 3, December 2020. josotl.indiana.edu 
within research courses. The group project or simulated research tasks may provide the environment necessary for the learning of soft skills (Zhang, 2012). This concept is also supported by Davidson \& Palermo (2015), who conducted a course project that consisted of a class research project that was led by the students themselves. Tasks included small group systematic literature reviews of the topic, the project itself, and completing a pre-post assessment of technical and broader skills. The project was evaluated as follows:

1. Activities: Class led project, small group tutorials.

2. Outcomes: Simple research study, systematic review, compare and contrast methods, use of qualitative and quantitative approaches, synthesis, communication and extension of communication skills and practices.

3. Assessment: Individual scientific paper, group literature review.

There are issues today surrounding the quality of research and critical thinking among college students. In this study, an overarching soft skill area - research competence - was addressed within, and outside of, the research skills curriculum. It was the goal of the study to assess the presentation of in-course and out-of-course competencies that are needed to develop a competent researcher who possesses the hard and soft skills necessary for one's eventual profession. An optimal blend of hard and soft skills may be critical to achieving excellence in leadership (Rao, 2013). Hard skills relate to an individual's ability to accomplish a particular task, whereas soft skills relate to individual attributes that can enhance one's personal interactions and performance within that task (Hendarman, 2012). Thus, the hard skills are technical in nature and the soft skills are all about self-management and interpersonal relations and how one deals when interacting with others (Laker, 2011). In addition to the acquisition of hard and soft skill competencies in research, the value of providing visual learning opportunities has also been of noted importance (White, Easton, \& Anderson, 2000; Berner \& Adams, 2004) when incorporated into classroom instruction.

The central purpose of this study was to examine research competence in undergraduate and graduate research classes that included targeted soft and technical research skills at a mid-western research university. A secondary purpose was to identify and assess key strategies designed to demonstrate research competence. The need to study research competence was intended to track and highlight areas of study both within and outside of a curriculum that improve one's ability to effectively conduct research and then qualitatively assess their effectiveness.

The importance of this study exists as a potential contributor to further standardization of research practices. While methodology protocols are typically taught in research courses, the methods employed to assess how effective research course content delivery is measured in providing a student with an ability to respond to the overall demands of a research study, is missing. These competencies are not easily observed or measured in the classroom setting, and they need to be identified and measured in more realistic environments. A student's observational skills, instrument development expertise, and other areas of competence often fail to be adequately addressed within the confines of a research course. Instead, there are competencies that one develops through trial and error when conducting research. While exposure to chief research protocol, standardized writing styles, and statistical applications exist in these courses, chief protocol for styles of research-oriented behavior when performing research tasks, are less apparent or non-existent in the classroom. Further, the utility of providing visual examples of researchers actually performing research projects is important in order to enhance student understanding of hard and soft skill competencies.

Journal of the Scholarship of Teaching and Learning, Vol. 20, No. 3, December 2020. josotl.indiana.edu 


\section{Literature Review}

This review involved the analysis of research that primarily address soft skills and methods typically engaged in when one is pursuing research of various potential job assignments. These two areas: understanding competence and teaching methods provide the framework within which student research abilities were assessed. Assessment methods, described in the methods section were designed to evaluate the attainment of competence, not only of the technical skills but also the soft skills needed to acquire that competency.

\section{Understanding Competence}

There are several variations on the definition of the concept known as competence. One generally accepted description of the concept is a connection between one's understanding, attitude, and skills that produce a satisfactory engagement in effective problem solving. Within academics, when the emphasis is on a curriculum based on competence, it is the integration of one's understanding, attitude, and skills. This is because on a professional level, any one of these three criteria in and of itself is not adequate to produce the desired behavior that is considered competent. In the marketplace, competency is the ability to combine in a specific way one's understanding, attitude, and skills that when applied appropriately, will accomplish a specific task. In sum, there are two components within most definitions of competence; a referral to a situation or context that involves a certain task or job; and, the assimilation of an individual's understanding, attitudes, and skills to accomplish said task or job (Baartman, 2007).

According to authors Showman, Cat, Cook, Holloway, and Wittman (2013), within the necessary skills for the undergraduate to develop effective conduction of research, there is a set of special traits that help the student to solve, in a successful manner, a research problem. These traits are: being organized, good judgment, effective communication, being creative, and being persistent. All of these necessary skills have equal importance for the student, progressing from learning how other people make discoveries, to making discoveries of their own. In applying the aforementioned five skills, the undergraduate student can go beyond being just a student to assuming the role of a researcher, thus transitioning from being a learner to a discoverer. When carrying out the technical aspects of a study, the five skills can be applied universally so that the student can pursue a path to becoming a more thorough, effective, and competent researcher. This essential set of personal skills supplies the student with a foundational framework for the student to succeed at becoming a researcher who can conduct productive and ethical research of the highest quality (Showman, 2013).

Continual improvement is an integral component of the educational process. Consequently, it is important for the assessment of an implemented program to set goals to meet educational objectives. This is accomplished through the initiation of activities intended to measure the achievement of individuals who are trying to reach targeted objectives and goals, to then implement necessary adjustments to a curriculum to ensure the quality of a program. The objectives and goals of a program that relate to the acquisition of soft skills need to be strategically identified then specified to formulate an efficiently organized program to address the required skills needed by the student for future employment. Achievement of these skills to meet goals and objectives of the educator and student can include several and various educational methods such as part-whole or whole-part-whole methods and activities that focus on the practice and presentation of soft skills (Beard, 2008). In the case of the assessment process, the secondary whole is where soft skills may be assessed after technical skills are accomplished.

Journal of the Scholarship of Teaching and Learning, Vol. 20, No. 3, December 2020. josotl.indiana.edu 


\section{Teaching Methodology}

Instruction of the whole part whole approach offers a balanced way to teaching (Bigelow, 2011). This is where students are presented with the whole picture of a project, then the whole is broken into small chunks to be reassembled back into the finalized whole (Clouse, 2013). These small chunks or parts play a particular role within the entire finalized whole project (Lam, 2014). According to researchers Swanson and Law, the learning model referred to as the whole-part-whole approach goes further than behavioristic, holistic, part whole, and whole part approaches to learning. This systematic approach is composed of two basic learning segments, a primary whole and a secondary whole. The primary whole initiates the learner to new material, providing an organized foundation for the student to effectively take in relevant concepts related to the learners' toolbox of abilities. The secondary whole is made up from parts within the primary whole that the teacher puts together after the students have satisfactorily completed the performance standards set for the individual parts of the primary whole (Swanson, 1993).

The whole-part-whole approach is a way to plan the material to be learned in a sequence that allows for better, more effective student comprehension. The model purports that within the process of learning, a natural cadenced pattern is developed based on the whole-part-whole concept. This can be accomplished by organizing the learning material into primary and secondary wholes. The primary whole, through the use of program materials such as summaries or prerequisites; prepares, orients, and motivates the learner toward the content of the instruction to be learned. The secondary whole represents the important instruction of the material, made up of parts that are connected in a logical order that provides meaning for the student to learn and acquire understanding. The acquisition of this new understanding of the instruction materials has to get transformed from active memory, to memory that is long-term. This is achieved through the incorporation of learning actively, e.g. by working on collaborative projects with others, assessment of self-performance, peer teaching, case studies, etc. Learning actively, reinforces the student's command of the parts of the material learned, that then can be synthesized into new understanding that helps the student prepare for additional learning (Karalis, 2011).

To illustrate this whole-part-whole approach, the following study by authors Wagner, Haibach, and Lieberman (2013) who conducted a study on the performance of motor skills on children with or without eyesight, is profiled. The principal participants of interest for the study consisted of 14 boys with a mean age of 10.00 years, and nine girls with a mean age of 10.44 years $(\mathrm{N}=23)$. The principal participants were diagnosed as being blind without any other disabilities. There was also a control group of children with eyesight, 15 boys with a mean age of 9.40 years and 13 girls with a mean age of 9.31 years $(\mathrm{N}=28)$. The 23 blind participants and the 28 participants with eyesight were tested with six locomotor tasks (leaping, hopping, running, galloping, sliding, and jumping), and six control of object tasks (kicking, catching, dribbling, throwing, and striking), for evaluation of their gross motor competency. For the study, instruction was to first teach the whole skill with the whole-part-whole approach. After the whole skill was fully comprehended by the participants, the instructor would break down the whole skill into its individual parts, and then teach each particular part of the skill to the participants. Once each child learned to practice the entire skill through the execution and refinement of each part, the participant would combine all of the parts together to carry out the complete skill. Results of the study confirmed that blind children are significantly impaired in the performance of locomotor tasks compared to children with eyesight. However, given time and practice, the blind participants could perform locomotor tasks as good as the sighted participants. For the practical purposes of the educator, the researchers recommended that it was crucial to begin the learning process with the whole-part-whole approach (Wagner, 2013).

Journal of the Scholarship of Teaching and Learning, Vol. 20, No. 3, December 2020. josotl.indiana.edu 


\section{The Value of Video Learning}

One cannot understate the potential value of visual learning in developing a greater understanding of research concepts. Carmichael, Reid \& Karpiche (2018) note that educational videos can increase student engagement, improve motivation, improve attention to learning, and increase student interest in the subject matter. They further assert that "many students indicate that they like learning from videos, empowering them to learn flexibly and independently, leading them to request online content in their courses. Because students enjoy and request access to video, it can be considered a positive instructional format which should provide confidence to librarians, faculty members, and other constituents, that as an educational resource it has a very bright future" (Carmichael, 2018).

Use of video learning has also been proven to be beneficial in the learning of foreign language. Hung (2009) noted that the use of video instruction tended to improve oral proficiency in gaining competence in language. While promising, not all researchers have found the value of the use of video learning. Yousef, Chatti, and Schroeder (2014) conducted a trial where a slide presentation was presented to two groups of students, one with instructor in the video and the other with just audio. There did not appear to be a benefit to see the instructor in this particular study; however, the benefits of video-enhanced instruction have proven to be popular with students (Giannakos 2013).

\section{Methods}

\section{Procedures}

The overall process involved assessment of undergraduate and graduate research competence through the development of competency-based assignments. Based upon a generic list of general competencies gleaned through the teaching of these courses, specific and discrete assignments were devised to support lectures on core topics. Students then completed these assignments, submitted them, and resubmitted if necessary, until the target level of competencies were attained.

The undergraduate classes consisted of senior level research courses, and the graduate classes were introductory level research courses. There was a differentiation made between the two types of courses; for example, in the undergraduate course, unless the student pursued graduate school, no further assessments were taken beyond an attained grade. While in the graduate course, further assessment beyond the course included theses and/or dissertations, qualifying examinations, journal writing and acceptance, and prerequisite course entry examinations. Overall, the effectiveness of a research video was also measured, and an assessment was made of student perceptions concerning the value of this video in increasing student understanding of what it takes to be a competent researcher. This video was developed by the researcher through three grants provided by the university for the express purpose of using the video to aid in the instruction of these classes (Author, 20012004). It also was made available for distribution by university media services to other national and international colleges and universities

\section{Subjects and Settings}

The study involved an eight-year (2008-2016), assessment of an intentional process of teaching soft and technical skills within a research class at the undergraduate and graduate level. Assessment protocol involved identification of what constitutes a research competence skill. These soft skills were generated from research texts and practice to include:

Journal of the Scholarship of Teaching and Learning, Vol. 20, No. 3, December 2020. josotl.indiana.edu 
1. Consistency (reliability).

2. Interview ability (able to effectively interview subjects).

3. Writing ability (flow and continuity of text).

4. Organizational protocol (accurately follow guidelines).

5. Statistical acumen (proficiency at basic calculations with statistical software).

6. Analytical ability (able to synthesize conclusions from data).

7. Resourcefulness (ability to draw upon available resources to accomplish goals). (Bennett, 2003; Henderson, 1991; Holcomb, 2002; Morse, 2009; Orcher, 2005; Pyrczak, 2006).

The above seven factors were deemed to be best measured with observational approaches. As a result, the study involved the following two main factors:

1. Evaluation of the effectiveness of technical research competence building assignments at the undergraduate and graduate levels.

2. Evaluation of visual learning tools for observing research competence in terms of specific soft skills.

\section{Research Assignments}

The instrumentation involved the creation of assignments in which students needed to achieve a target level of competency to receive a passing competency grade. Table 1 provides references to the type and location of each assigned task. It can be noted that in combination, these assignments built upon each successive assignment to culminate in the conclusion of a final course project in each class. Also each assignment, per se, was useful to elicit a particular skill set within a research area of competence that was expected as an outcome measure.

Assignments consisted of a series of seven steps in each of two levels, undergraduate and graduate, designed to be a progressive accumulation of competence throughout the course. Each level is described below:

Undergraduate exemplars within the research course consisted of the following:

1. Benefits Questions: Read and react to an issue in research.

2. The purpose of this inaugural exposure to research was to elicit an understanding of research-based inquiry within the profession. Students were given an article that identified the benefits of recreation and leisure in the daily lives of individuals. Students were asked to respond to three questions about this article.

3. Journal Article Guided Critique: This assignment was more extensive in analyzing a research article selected by the student. The intention was to determine if students understood what constitutes a research article, to then guide them along a series of questions that allowed them to dissect the article and glean important details.

4. Database search and retrieval: Students were then given a tour of the library database search and retrieval system. After the in-class workshop, they were given an assignment to locate sources for a topic of interest to them, using keyword searches and other means to collect a series of relevant research articles. They then selected 10 of the most relevant articles that appeared in different forms (dissertations, magazine articles, journal articles, government publications, and other exemplars). A summary of the database search and number of articles attained along with 10 citations using the format of the American Psychological Association (APA), were submitted for review and grading.

Journal of the Scholarship of Teaching and Learning, Vol. 20, No. 3, December 2020. josotl.indiana.edu 
5. Quantitative Data Analysis Project: This project involved the class in several ways. Early in the course, the instructor distributed a questionnaire to the class for their completion. In the distribution process, proper protocol for securing subjects was modeled by the instructor so that students could elect to decline participation. This questionnaire included a topic that was of interest to the class (spring break plans, fitness endeavors, or another topic). Students completed and returned the survey. Results were then entered into a database for further study. In a classroom computer workshop, the instructor demonstrated the way in which the Statistical Package for the Social Sciences (SPSS) is used to analyze data. Students were then shown a sample of the results of the survey in the class as a demonstration. They then were assigned the completion of several data analysis problems using this data: frequencies, percentages, cross-tabulations, and graphics. Their completed assignment included printouts of the problems with a narrative paragraph analyzing the results.

6. Qualitative Data Analysis Project: Students were given a lecture about the purposes and processes of qualitative data analysis. They were then assigned to go observe students in a data gathering area within the university. They recorded observations through note taking on a form that elicited subject behaviors, interpretation of these behaviors, analysis of the behaviors, and personal notes. After observing, students formed two interview questions to ask three subjects. They recorded the answers by taking notes. A lecture in class then covered coding methodology for field notes including a three-part manual perusal of the notes, writing of analytical memos, and the process of analyzing qualitative information. Students coded and wrote an analytical memo of their observations and interviews and submitted this for a grade. In the class following the due date, students shared their observations with each other. The varying themes that emerged from their coding analysis were discussed within the context of how a researcher can collect a preponderance of material over an extended period that may cover all the themes discovered by all of the students involved in the assignment.

7. Research Proposal: Students, either in a group or individually, actually identified a research topic to propose, using the protocol of a research proposal: Introduction, Literature Review (modified), and Methodology. Earlier course assignments, designed to support portions of this project, were intended to guide the student through the assignment. The proposal was submitted in two parts: 1) Introduction and Literature Review, and 2) Methodology. Introduction and Methodology included the standard protocol for either quantitative or qualitative methodology. The literature "review" consisted of an annotated bibliography of four articles that supported the research topic. If used as a group project, students submitted four articles each to comprise the combined literature review. Students were then evaluated according to their written proposal and their presentation. This evaluation formed the capstone grade in the course. Students could resubmit the written proposal once as a draft review before final submittal.

8. Research Proposal Presentation: Students then presented their proposal in either an oral narrative or poster presentation that outlined their topic. These were either in a group or individual format, depending upon the type of assignment for the semester.

9. Research Video: Students were given either a viewing of the full video or segments of the video in each class. They then completed a questionnaire that elicited their overall impressions of the utility of the video in assisting their learning processes.

Journal of the Scholarship of Teaching and Learning, Vol. 20, No. 3, December 2020. josotl.indiana.edu 
Graduate exemplars within the research course consisted of the following:

1. Journal Article Critique: Students were asked to locate an article in their area of interest and complete a detailed analysis using a set of guided questions. This assignment was similar to the undergraduate student assignment, although the guided questions were more detailed.

2. Database Search and Retrieval: Students were first given an in-class library database search and retrieval workshop. They were then assigned to present the results of an extensive search process that involved identification of databases, keywords, and numbers of articles per key word. They then submitted 25 articles in APA format. These articles formed an initial base of a literature review that was likely to result in forming future master's and doctoral manuscripts that were end outcomes of the degree, and used outside of the course.

3. Literature Review: Students were then assigned to provide an initial look at a literature review. It consisted of an outline of a topic following a statement of the problem and purpose of the study. They then submitted a written narrative of at least one of the topics, using proper APA citation format within and outside of the text. They were expected, after submittal of the assignment and through consultation with the instructor and their advisor, to continue writing the full review.

4. Problem Statement: Students then used their literature findings to formulate a problem statement that included introduction, statement of the problem, purpose of the study, significance, delimitations, limitations, assumptions, hypotheses or research questions, and definitions of key terms. This part of the assignment was reviewed by the instructor and used in consultation with the student, to refine the topic of interest.

5. Methodology: Students then submitted the methodology chapter to include a restatement of the problem and purpose, administration of the study, subject and sample information, instrumentation, data collection, and data analysis procedures.

6. Research Proposal: Students then submitted a rough draft and subsequently, the final form of a research proposal. These were submitted and later discussed with the student and the instructor, as well as a topic advisor. The proposal culminated with students presenting their proposals in a formal research assembly that consisted of the class, faculty, students in the school, and invited guests. The students presented either a poster or a formal oral narrative of 15 minutes with five minutes for questions.

7. Research Video: The graduate students also were shown a research video in segments or as a total viewing experience and then surveyed as to their impressions of the video in assisting their overall learning experience. These exemplars comprised the structure of the courses taught, and they represented an increasingly complex development of skills over the duration of the course.

\section{Analysis of Outcomes}

Table 1 shows the type of exemplar, purpose, and its usage within each of the courses. In addition, methods of evaluation and feedback are noted for each exemplar. Inter-rater reliability was addressed through training sessions that profiled a common procedure for distribution of the evaluation mechanisms for each of the items evaluated in Table 1 and Table 2.

Journal of the Scholarship of Teaching and Learning, Vol. 20, No. 3, December 2020. josotl.indiana.edu 
Table 1. Intended course outcomes in chronological order of delivery

\begin{tabular}{|c|c|c|c|c|}
\hline Assignment & Level & Purpose & Usage & Method \\
\hline $\begin{array}{l}\text { Benefits } \\
\text { Questions }\end{array}$ & UG & $\begin{array}{l}\text { To begin the } \\
\text { process. }\end{array}$ & $\begin{array}{l}\text { Individual } \\
\text { Assignment }\end{array}$ & $\begin{array}{l}\text { Read article and } \\
\text { complete } \\
\text { questions. }\end{array}$ \\
\hline $\begin{array}{l}\text { Journal Article } \\
\text { Critique }\end{array}$ & $\mathrm{UG} / \mathrm{G}$ & $\begin{array}{l}\text { To expand skills } \\
\text { in research } \\
\text { reading. }\end{array}$ & $\begin{array}{l}\text { Individual } \\
\text { Assignment }\end{array}$ & $\begin{array}{l}\text { Select article and } \\
\text { analyze with } \\
\text { guided } \\
\text { questionnaire. }\end{array}$ \\
\hline Database Search & $\mathrm{UG} / \mathrm{G}$ & $\begin{array}{l}\text { To use databases } \\
\text { effectively to } \\
\text { secure research } \\
\text { studies. }\end{array}$ & $\begin{array}{l}\text { In-class and } \\
\text { follow-up }\end{array}$ & $\begin{array}{l}\text { Students use a } \\
\text { keyword search of } \\
\text { selected databases } \\
\text { and report cited } \\
\text { findings. }\end{array}$ \\
\hline $\begin{array}{l}\text { Quantitative } \\
\text { Data Project }\end{array}$ & UG & $\begin{array}{l}\text { To analyze data } \\
\text { sets. }\end{array}$ & Class & $\begin{array}{l}\text { Students fill out } \\
\text { questionnaire } \\
\text { about their habits } \\
\text { and then run } \\
\text { statistics through } \\
\text { SPSS. }\end{array}$ \\
\hline $\begin{array}{l}\text { Qualitative Data } \\
\text { Project }\end{array}$ & UG & $\begin{array}{l}\text { To learn } \\
\text { observation and } \\
\text { interview } \\
\text { techniques. }\end{array}$ & Group & $\begin{array}{l}\text { Students observe, } \\
\text { take research } \\
\text { notes, and } \\
\text { interview others in } \\
\text { a selected setting. }\end{array}$ \\
\hline $\begin{array}{l}\text { Research } \\
\text { Proposal and } \\
\text { Presentation }\end{array}$ & $\mathrm{UG} / \mathrm{G}$ & $\begin{array}{l}\text { Learn the art of } \\
\text { proposal } \\
\text { preparation and } \\
\text { presentation. }\end{array}$ & $\begin{array}{l}\text { Individual or } \\
\text { Group }\end{array}$ & $\begin{array}{l}\text { Students write a } \\
\text { proposal and } \\
\text { present it to a } \\
\text { group. }\end{array}$ \\
\hline Literature Review & G & $\begin{array}{l}\text { To identify } \\
\text { strategies in } \\
\text { completing a } \\
\text { written literature } \\
\text { review. }\end{array}$ & Individual & $\begin{array}{l}\text { Students begin the } \\
\text { process of } \\
\text { selecting a main } \\
\text { topic to write } \\
\text { from research } \\
\text { gathered. }\end{array}$ \\
\hline $\begin{array}{l}\text { Problem } \\
\text { Statement }\end{array}$ & G & $\begin{array}{l}\text { To learn the } \\
\text { components of } \\
\text { statement of the } \\
\text { problem. }\end{array}$ & Individual & $\begin{array}{l}\text { Students write } \\
\text { who, what, and } \\
\text { why of their } \\
\text { problem. }\end{array}$ \\
\hline Research Video & $\mathrm{UG} / \mathrm{G}$ & $\begin{array}{l}\text { To identify } \\
\text { appropriate } \\
\text { research methods } \\
\text { for a particular } \\
\text { topic }\end{array}$ & Individual & $\begin{array}{l}\text { Students evaluate } \\
\text { impressions of the } \\
\text { video as a teaching } \\
\text { aide. }\end{array}$ \\
\hline
\end{tabular}

Note. UG = Undergraduate; $\mathrm{G}=$ Graduate. 
The effectiveness of each assignment in developing research competence was measured via the open-ended section of the course evaluation form that specifically elicited impressions students had of the assignments. This open-ended form was given to the students at the conclusion of each course as per university policy and was a separate section from the standard course evaluation form. It was administered to eight years of research classes taught at the graduate and undergraduate level. The open-ended responses were examined through a manual three-part coding process and grouped according to the type of impression. Table 2 involves an assessment of learning objectives of each of the assessment tools used in the study. Numbers appearing in the third column of the table represent the type of soft skill tested in each assignment. Commentary is made on the relative success of seeing these skills during the review and grading of the assignment. In the "Comment" section of the table, the soft skill that it is referred to is reassessed as the intended outcome of the assignment. In particular, by focusing on only the soft skill for each assignment, it was possible to glean a pattern for how a soft skill may provide an important framework for the development of research skills. For example, the open-ended "Benefits" assignment allows an instructor to see writing ability and to build from that initial observation to encourage increased attention to this soft skill. These assessments rounds out the student's ability to conduct research and persevere through a study.

As a result of the analysis, the themed sections in Table 2 were formulated, and an evaluation of the Measured Soft Skill was shared. The numbers refer to the code below the table originating from the criteria listed in the subjects and Settings section of this article. It shows that students believed to be helped in gaining these skills and that the students valued the video as an enhancement tool.

Table 2. Assessment of learning effectiveness

\begin{tabular}{|c|c|c|c|c|}
\hline Assignment & $\begin{array}{l}\text { Basis for } \\
\text { Evaluation }\end{array}$ & $\begin{array}{l}\text { Measured Soft } \\
\underline{\text { Skill* }}\end{array}$ & Outcome & Comment \\
\hline Benefits & $\begin{array}{l}\text { Points assigned } \\
\text { upon completion }\end{array}$ & 3 & $\begin{array}{l}\text { Effective as a } \\
\text { warm up for the } \\
\text { research skill } \\
\text { development }\end{array}$ & $\begin{array}{l}\text { Initial value in } \\
\text { assessing } \\
\text { writing, helpful } \\
\text { in assessing } \\
\text { student interest }\end{array}$ \\
\hline $\begin{array}{l}\text { Journal Article } \\
\text { Critique }\end{array}$ & $\begin{array}{l}\text { Points assigned } \\
\text { according to a } \\
\text { scale of } \\
\text { completion }\end{array}$ & 6 & $\begin{array}{l}\text { Revealed areas } \\
\text { where students } \\
\text { needed more } \\
\text { exposure to } \\
\text { research }\end{array}$ & $\begin{array}{l}\text { Helpful in } \\
\text { assessing raise } \\
\text { student } \\
\text { research } \\
\text { interest. }\end{array}$ \\
\hline Database Search & $\begin{array}{l}\text { Completion of a } \\
\text { questionnaire }\end{array}$ & 5 & $\begin{array}{l}\text { Development of } \\
\text { investigatory } \\
\text { skills }\end{array}$ & $\begin{array}{l}\text { Useful for } \\
\text { taking a } \\
\text { student } \\
\text { through a data } \\
\text { set and } \\
\text { familiarize. } \\
\text { Showed } \\
\text { relevance to } \\
\text { student interest }\end{array}$ \\
\hline
\end{tabular}

Journal of the Scholarship of Teaching and Learning, Vol. 20, No. 3, December 2020. josotl.indiana.edu 


\begin{tabular}{|c|c|c|c|c|}
\hline $\begin{array}{l}\text { Quantitative } \\
\text { Data Project }\end{array}$ & $\begin{array}{l}\text { Review of } \\
\text { completed } \\
\text { questionnaire } \\
\text { taken by students }\end{array}$ & 5 & $\begin{array}{l}\text { Piqued interest in } \\
\text { student results }\end{array}$ & $\begin{array}{l}\text { Showed } \\
\text { relevance to } \\
\text { student interest }\end{array}$ \\
\hline $\begin{array}{l}\text { Qualitative Data } \\
\text { Project }\end{array}$ & $\begin{array}{l}\text { Assessment of } \\
\text { completed sheet } \\
\text { of } \\
\text { notes }\end{array}$ & 2 & $\begin{array}{l}\text { Demonstration } \\
\text { of observational } \\
\text { ability and } \\
\text { analytical } \\
\text { strength }\end{array}$ & $\begin{array}{l}\text { "Opened eyes" } \\
\text { as to usefulness } \\
\text { of notes and } \\
\text { extensiveness } \\
\text { of observe on } \\
\text { techniques }\end{array}$ \\
\hline $\begin{array}{l}\text { Research } \\
\text { Proposal and } \\
\text { Presentation }\end{array}$ & $\begin{array}{l}\text { Strength assessed } \\
\text { according to } \\
\text { completion }\end{array}$ & $1,6,4$ & $\begin{array}{l}\text { Demonstrated } \\
\text { critical thinking } \\
\text { based on review } \\
\text { of } \\
\text { logic }\end{array}$ & $\begin{array}{l}\text { Challenged } \\
\text { students } \\
\text { thinking }\end{array}$ \\
\hline Literature Review & $\begin{array}{l}\text { Graded on } \\
\text { extensiveness } \\
\text { and } \\
\text { thoroughness }\end{array}$ & 3,7 & $\begin{array}{l}\text { Opened eyes to } \\
\text { the need for } \\
\text { broadening scope }\end{array}$ & $\begin{array}{l}\text { Great } \\
\text { preparation for } \\
\text { any research } \\
\text { endeavor }\end{array}$ \\
\hline $\begin{array}{l}\text { Problem } \\
\text { Statement }\end{array}$ & $\begin{array}{l}\text { Graded or logical } \\
\text { model }\end{array}$ & 4 & $\begin{array}{l}\text { Challenged one's } \\
\text { ability to reason }\end{array}$ & $\begin{array}{l}\text { Useful for } \\
\text { assessing logic }\end{array}$ \\
\hline Research Video & Questionnaire & 4 & $\begin{array}{l}\text { Seeing research } \\
\text { in action }\end{array}$ & $\begin{array}{l}\text { Motivational } \\
\text { for students to } \\
\text { see the hard } \\
\text { soft skill in } \\
\text { action }\end{array}$ \\
\hline
\end{tabular}

*Listed under Subjects and Settings section of article: $1=$ Consistency, $2=$ Interview Ability, 3=Writing Ability, 4=Organizational Protocol, 5=Statistical Acumen, 6=Analytical Ability, $7=$ Resourcefulness

The second phase of the evaluation specifically referred to the utility of the research video that was produced for the course. Encompassing both courses was the assessment of a research video designed by researchers from within the school. Vignettes ranged from quantitative to qualitative methods, describing data collection techniques that were either shown in segments or in its entirety. A questionnaire, separate from the end of course evaluation was administered to the students to gauge the preferred mode of viewing and their response/reaction to the usefulness of the information in the video. The data from the questionnaire were then analyzed, with the analysis (shown in Table 3) and according to the criteria (noted below) in order to guide the instructional use and effectiveness of this video in class lectures.

The following examples of impressions are shown in Table 3 regarding the viewing of the research video. 


\section{Table 3. Informative comments regarding video}

Informative and intelligent - could show research actually being conducted.

Very well organized in content but not much visual appeal. We are just watching people talk. A lot of good info about qualitative research. Video topic and presentation much more interesting but still had trouble understanding purpose of study, what she hoped to attain.

I think films are better if more people talk than just 1 or 2 people - more people the better.

Losing interest in the topic very quickly.

Topic was interesting.

Tone down the lighting; each person looks as if they haven't seen the sun in years.

More interesting than the one about elderly people's balance.

The list of disadvantages was helpful in conveying the information.

Discuss what is going on beforehand.

The problem with research as an academic subject is that although it is important to know and understand, it is difficult to captivate interest. In addition, the research video, newly developed by the instructor and evaluated in class, yielded impressions on quantified questionnaires that elicited evaluation of the following criteria on a scale of 1-5, 1 being the greatest impression and 5 being the least impression:

1. Clarity (accuracy of content).

2. Visual Appeal (organized and professional).

3. Interest (continuity and flow of material).

4. Quality (imparted value of course).

5. Content (information quality).

6. Utility (usefulness).

7. Understanding (ease of grasping main concepts).

8. Overall Goal Attainment (ability to plan and execute goals).

Furthermore, an open-ended "Other" comment area allowed students to make specific recommendations for the final editing of the video. The video, "Research Design" was tested in undergraduate and graduate classes offered during one semester. It represented the first part of a three part series intended to demonstrate research concepts and competencies of faculty and students in the school. Students were shown research topics of current actual studies going on at the time of video recording that represented the continuum of both quantitative and qualitative studies.

T-tests for independent samples were employed to determine if there were significant differences $(p \leq 0.05)$ between the two graduate classes and between segments shown in the undergraduate classes. Table 4 shows that there were significant differences in a few qualities with the undergraduate classes; however, there was not a significant difference between the two graduate classes tested.

Table 4. Differences between quality indicators

\begin{tabular}{lcccc}
\hline Visual Appeal & $.014(1 / 5)^{*}$ & $.008(3 / 5)$ & $.004(4 / 5)$ & $.016(2 / 5)$ \\
Interest & $.014(1 / 5)$ & $.035(3 / 5)$ & & \\
\hline
\end{tabular}

Note. $*$ Refers to sections of the research video. Section $1=$ Balance analysis of older adults study; Section 2 = Gait analysis of Down syndrome babies study; Section 3 = Community survey with

Journal of the Scholarship of Teaching and Learning, Vol. 20, No. 3, December 2020. josotl.indiana.edu 
Boys and Girls club study; Section $4=$ Leisure in the life of people with mental illness study; Section 5 = Sudan refugee field study.

Open-ended comments for the viewing of the test video showed a range of comments that included the following groupings of remarks:

1. Low to high interest level.

2. Shorten lengths.

3. Increase font size of captioning text.

4. Increase visuals and decrease interviews.

5. Positive overall response.

These suggestions were incorporated for the final version of the video, with two subsequent videos in the series following through with suggestions on length, format, and increase of visuals. Table 5 is a summary of comments that were noted by students as a result of the pilot viewing of the video.

Table 5. Overall impression of video

\begin{tabular}{|c|c|c|c|}
\hline Statement Category & Sequencing & Assignment Quality & Future Benefit \\
\hline Assignments. & $\begin{array}{l}\text { "Ok. It worked the way } \\
\text { to the total end paper, } \\
\text { which helped." }\end{array}$ & $\begin{array}{l}\text { "Most assignments were } \\
\text { beneficial." }\end{array}$ & $\begin{array}{l}\text { "Help a lot in the } \\
\text { future." }\end{array}$ \\
\hline End course project. & $\begin{array}{l}\text { "Helped prepare us for } \\
\text { the big project." }\end{array}$ & $\begin{array}{l}\text { "Yes, but working in } \\
\text { groups would have been } \\
\text { much better." }\end{array}$ & $\begin{array}{l}\text { "Helped put } \\
\text { information toward } \\
\text { the field of research." }\end{array}$ \\
\hline \multirow{5}{*}{$\begin{array}{l}\text { Overall impression } \\
\text { of course } \\
\text { assignments. }\end{array}$} & $\begin{array}{l}\text { "Gave us a chance to } \\
\text { work on the project." }\end{array}$ & $\begin{array}{l}\text { "Amount of work made } \\
\text { it difficult to benefit." }\end{array}$ & \\
\hline & $\begin{array}{l}\text { "Helped extremely for } \\
\text { the final project." }\end{array}$ & "Very tedious." & \\
\hline & $\begin{array}{l}\text { "Load spread through } \\
\text { entire semester." }\end{array}$ & "Not very." & \\
\hline & $\begin{array}{l}\text { "Beneficial but points } \\
\text { awarded did not equal } \\
\text { work." }\end{array}$ & "Too difficult and long." & \\
\hline & "Project more helpful." & "Fewer assignments." & \\
\hline
\end{tabular}

\section{Discussion}

The undergraduate whole-part-whole approach to student assessment placed $50 \%$ of the course grade on a semester long project that featured each skill culminating into a final project. In this process, small groups of four to five students composed and implemented a park user survey, analyzed the gathered data, composed a term paper, and presented an informational poster of the project. For the term paper, the groups worked on the following individual parts, each building on the previous part: abstract, introduction, literature review, methods section, data collection and entry, results section, title page, references and formatting. The remainder of student assessment for the course was based 
on: in-and-out of class activities (16\%), midterm examinations $(22 \%)$, and three written personal reflections of their experiences $(12 \%)$.

The graduate course used a whole-part-whole method involving 50\% of the class who were involved in separate assignments as noted in Table 1. The result culminated in a term paper on a selected topic of interest that featured an introduction, literature review, and methods. The term paper was worth $25 \%$ and examinations and quizzes comprised the remaining point totals, points were assessed for each assignment accomplished. Students in the classes could resubmit their papers after getting feedback from the instructor. It was found that, in terms of understanding, students achieved similar results in the soft and hard skills assessments; however, those with the end product of an actual study and presentation fared better in understanding the process of research. Further, evaluation of the research video was helpful to some extent as a replacement of the actual project, but only in part, since the students did not internalize the video as they did the project.

The findings were useful as a test of assessment of research competence and the development of soft skills; in that, within each class situation, the students had to persevere through a series of assignments that not only tested a hard skill, but the skills of consistency, interview ability, writing ability, organizational protocol, statistical acumen, analytical ability and resourcefulness: all were tested to a greater or lesser extent within each assignment. In evaluating soft skill development, it was determined that the end course group project tested soft skill attainment the most. This was because each group needed to stay on track to complete the task all semester. It was determined that the video use was effective in giving students a picture of how several researchers actually conducted research, offering different forms of research to give students a wide range to options; however, if not attached to an actual project, it was not as helpful.

\section{Conclusions}

The study of in-course and out-of-course approaches to research competence addresses two main issues:

1. Is the development of research competence per se, an intentional outcome of the pursuit of a college major?

2. How are soft and hard skills measured effectively as an outcome of an educational program: through courses, testing instruments, and other means?

It was determined that in this case, the development of research competency should be implemented in a course, through individual and group assignments, that may be accomplished to meet minimum standards and, if necessary, repeated until that standard is met:

1. Within an overall departmental approach to ensure that students achieve minimal research capability, and;

2. Within the context that research support exists to allow students to develop research competence independently.

The main purpose of this study was to examine research competence in undergraduate and graduate research classes that included targeted soft and hard research skills. When students worked at accomplishing a hard skill related to an assignment, they had to develop and use soft skills. To be productive at completing an assignment, some students realized that they needed to develop a mindset toward being organized, having good judgment, being an effective communicator, being creative, and being persistent to meet targeted goals. However, not all students were able to acquire a competent

Journal of the Scholarship of Teaching and Learning, Vol. 20, No. 3, December 2020. josotl.indiana.edu 
level of these skills because they were not attuned to the research process, consequently these students did not feel confident with some aspects of conducting a research inquiry, such as: hypothesis testing.

The secondary purpose was to identify and assess key strategies designed to demonstrate research competence. The main key strategy was to give students the whole picture of the final goal of the course, and then to structure each hard skill assignment so that the accomplishment of one assignment laid the foundation for the following assignment. This created an opportunity for the student to develop the soft skills necessary to achieve each successive assignment. Another main key strategy was to provide the students with assignments that would give them experiences related to the process of conducting a research project. Whether the assignment was in class or in the field, the student was challenged to find ways to accomplish the goal of the assignment. This strategy may have been effective for students who immersed themselves into accomplishing each assignment, potentially developing their soft skills and their research competence along the way. While some students, possibly due to a lack of interest, may have not put much effort into completing the assignments, thus possibly lacking in competence to perform some research skills. Nonetheless, those students who participated in an actual study and subsequent oral presentation fared better in understanding the process of performing a research project.

The need to study research competence was intended to track and highlight areas of study both within the classroom and in the field, to provide a curriculum that would improve one's ability to effectively conduct research. The effectiveness of a research video was also measured, and an assessment was made of student perceptions concerning the value of this video in increasing student understanding of what it takes to be a competent researcher.

The two-fold importance of this study exists as a potential contributor to further standardization of research practices and as a reinforcement of the value of reality-based visual learning tools, such as the research video. With standardization and refinement of courses that teach and promote the development of hard and soft research skills, the student may acquire the proficiency to thoroughly and competently carry out a research project. It may be that there is a need for more than one research skills course, possibly one course focusing on the individual and one course focusing on the small group project. It is recommended that this research competency assessment be duplicated at other universities and their results compared with the results of this study. Furthermore, the ongoing assessment of research competence may ensure that students will be more confident and capable of being more effective when addressing research assignments both in the practical professions they choose and/or their academic pursuits.

In addition, the value of visual active learning cannot be over-emphasized. Students were able to see how research actually unfolds by viewing expert faculty members in the field conducting many different types of studies. By actually seeing the purpose, methods, and results in real time, students increased their understanding of the value of being competent and thorough when conducting research studies. In addition, the benefit of video learning (Berner \& Adams, 2004) as it pertains to the future value of online instruction also provides a positive future for developing competent researchers.

Journal of the Scholarship of Teaching and Learning, Vol. 20, No. 3, December 2020. josotl.indiana.edu 


\section{References}

Arellano, E. R., Morano, Lourdes N., Nepomuceno, Cherry T. (2012). Assessing undergraduate research competence: Readiness for research-oriented jobs. LCCB Development Education Journal of Multidisciplinary Research, 1(2), 92-116.

Author (2001-2004). Research design: Part III. Bloomington, IN: Indiana University.

Baartman, L. K., Bastiaens, Theo J., Kirschner, Paul A., van der Vleuten, Cees P.M. (2007).

Evaluating assessment quality in competence-based education: A qualitative comparison of two frameworks. Educational Research Review, 2(2), 114-129.

Beard, D., \& Schwieger, D. (2008). Integrating soft skills assessment through university, college, and programmatic efforts at an AACSB accredited institution. Journal of Information Systems Education(2), 229.

Bennett, J. O., Briggs, W. L., \& Triola, M. F. (2003). Statistical reasoning for everyday life (2nd ed.): Boston: Addison-Wesley.

Berner, E. S., \& Adams, B. (2004). Added value of video compared to audio lectures for distance learning. International Journal of Medical Informatics, 73(2), 189-193.

Best, J. (2001). Telling the truth about damned lies and statistics. The Chronicle Review, 47(34).

Bigelow, M., \& Vinogradov, P. (2011). Teaching adult second language learners who are emergent readers. Annual Review of Applied Linguistics, 31, 120-136. doi:10.1017/S0267190511000109

Carmichael, M., Reid, A. K., \& Karpicke, J. D. (2018). Assessing the impact of educational video on student engagement, critical thinking and learning: The current state of play. White paper, Sage Publishing, available at: https://au. sagepub.com/en-gb/oce/press/what-impact-doesvideo-have-on-student-engagement (accessed April 2020).

Clouse, R. W., Goodin, T., Aniello, J., McDowell, N., \& McDowell, D. (2013). Leadership metaphors: Developing innovative teaching strategies. American Journal of Management, 13(1), 79.

Coleman, C. H. (2009). Vulnerability as a regulatory category in human subject research. Journal of Law, Medicine and Ethics, 37(1), 12-18. https://doi.org/10.1111/j.1748-720X.2009.00346.x

Davidson, Z. E., Palermo, Claire. (2015). Developing research competence in undergraduate students through hands on learning. Journal of Biomedical Education, 2015, 1-9. https://doi.org/10.1155/2015/306380

Durlak, J. A., Weissberg, Roger P., Dymnicki, Allison B., Taylor, Rebecca D., Schellinger, Kriston B. (2011). The impact of enhancing students' social and emotional learning: A meta-analyis of school-based universal interventions. Child Development, 82(1), 405-432.

Giannakos, M. (2013). Exploring the video-based learning research: A review of the literature. British Journal of Educational Technology, 44(6), 191-195.

Gibert, A., Tozer, Wade. C., Westoby, Mark. (2017). Teamwork, soft skills, and research training. Trends in Ecology and Evolution, 32(2), 81-84.

Hendarman, A. F., \& Tjakraatmadja, J. H. (2012). Relationship among soft skills, hard skills, and innovativeness of knowledge workers in the knowledge economy era. Procedia - Social and Behavioral Sciences, 52, 35-44. doi:10.1016/j.sbspro.2012.09.439

Henderson, K. A. (1991). Dimensions of choice: A qualitative approach to recreation, parks, and leisure research. State College, PA:Venture Publishing.

Holcomb, Z. C. (2002). Interpreting basic statistics: A guide and workbook based on excerpts from journal articles. Glendale, CA: Pyrczak Publishing.

Hornung, C. A., Jones, Carolynn. T., Calvin-Naylor, Nancy A., Kerr, Jared., Sonstein, Stephen A., Hinkley, Terri., Ellingrod, Vicki L. (2018). Competency indices to assess the knowledge,

Journal of the Scholarship of Teaching and Learning, Vol. 20, No. 3, December 2020. josotl.indiana.edu 
skills and abilities of clinical research professionals. International Journal of Clinical Trials, 5(1), 46-53.

Hung, H.T. (2009). Learners' perceived value of video as mediation in foreign language learning. Journal of Educational Multimedia and Hypermedia, 18(2), 171-190. Waynesville, NC USA: Association for the Advancement of Computing in Education (AACE). Retrieved April 18, 2020 from https://www.learntechlib.org/primary/p/26978/.

Kahn, J. P., \& Mastroianni, A. C. (2002). Doing research well by doing right. Chronicle of Higher Education, 48(23), 24.

Karalis, T., \& Vorvilas, G. (2011). Designing multimedia learning material for adult education: An interdisciplinary approach. Review of Science, Mathematics and ICT Education, 5(2), 85-108.

Laker, D. R., \& Powell, J. L. (2011). The differences between hard and soft skills and their relative impact on training transfer. Human Resource Development Quarterly, 22(1), 111-122. doi:10.1002/hrdq.20063

Lam, H. C. (2014). Elaborating the concepts of part and whole in variation theory: The case of learning chinese characters. Scandinavian Journal of Educational Research, 58(3), 337-360. doi:10.1080/00313831.2012.732604

McCrystal, P. (2000). Developing the social work researcher through a practitioner research training programme. Social Work Education, 19(4), 359-373. doi:10.1080/02615470050078366

Morse, M., \& Niehaus, L. (2009). Mixed method design: Principles and procedures. Walnut Creek, CA: Left Coast Press.

Orcher, L. T. (2005). Conducting research: Social and behavioral science methods. Glendale, CA: Pyrczak Publishing.

Providing researchers with the skills and competencies they need to practise open science. (2017). Retrieved from Luxembourg: https://ec.europa.eu/research/openscience/pdf/os skills wgreport final.pdf.

Pyrczak, F. (2006). Making sense of statistics: A conceptual overview (4th ed.). Glendale, CA: Pyrczak Publishing.

Rao, M. S. (2013). Smart leadership blends hard and soft skills: ... and emphasizes the importance of continuous learning. Human Resource Management International Digest, 21. doi:10.1108/HRMID04-2013-0023.

Research competencies framework (2007). Retrieved from London, United Kingdom: https://www.fgdp.org.uk/files/docs/in-practice/Research/research\%20comtetencies.pdf.

Showman, A., Cat, L. A., Cook, J., Holloway, N., \& Wittman, T. (2013). Five essential skills for every undergraduate researcher. CUR Quarterly, 33(3), 16-20.

Small, M. F. (2000, 11/17/). Owing a written explanation to the widest possible audience. Chronicle of Higher Education, p. B5. Retrieved from http://proxyiub.uits.iu.edu/login?url=https://search.ebscohost.com/login.aspx?direct=true $\& \mathrm{db}=f 5 \mathrm{~h} \& \mathrm{AN}=3767334 \&$ site $=\mathrm{eds}-\mathrm{live} \& \mathrm{scope}=$ site.

Swanson, R. A., \& Law, B. D. (1993). Whole-part-whole learning model. Performance Improvement Quarterly, 6(1), 43-53.

Wagner, M. O., Haibach, P. S., \& Lieberman, L. J. (2013). Gross motor skill performance in children with and without visual impairments-Research to practice. Res Dev Disabil, 34, 3246-3252. doi:10.1016/j.ridd.2013.06.030

Watson, A. (1994). Strategies for the assessment of competence. The Vocational Aspects of Education, 46(2), 155-165. doi:10.1080/0305787940460205

White, E. M. (2000). Bursting the bubble sheet: How to improve evaluations of teaching. The Chronicle of Higher Education. 
White, C., Easton, P., \& Anderson, C. (2000). Students' perceived value of video in a multimedia language course,.Journal of Educational Media International, 37(3), 167-175.

Yudof, M. G. (2002). Is the public research university dead? Chronicle of Higher Education, 48(18), 24.

Yousef, A., Chatti, M., \& Schroeder, U. (2014). Video-Based Learning: A critical analysis of the research published in 2003-2013 and future visions. In eLmL 2014, The Sixth International Conference on Mobile, Hybrid, and On-line Learning, 112-119.

Zhang, A. (2012). Peer assessment of soft skills and hard skills. Journal of Information Technology Education: Research, 11(1), 155-168. 